\title{
Pencil Grip Patterns of Students and Skilled Workers
}

\author{
Jaiyeoba Ojigho Jennifer Efe, ${ }^{1}$ Odokuma Emmanuel Igho ${ }^{1}$ \\ ${ }^{1}$ Delta State University Abraka, Delta State, Nigeria
}

\begin{abstract}
Background: Pencil grip can be defined via detailed descriptions of the variables constituting the grip and it commences in the preschool years with writing instruments and therefore relevant to graphologists, forensic medicine and anthropology. The purpose of this investigation was to describe the diversity of pencil grip patterns among students and skilled workers in Delta State, Nigeria. The research also aimed at determining the effects of sociodemographic factors, handedness, and handwriting speed on pencil grip patters. Methods: Stratified random sampling was employed in this cross sectional observational study. Five hundred and fourty three volunteers between the ages of 11-77 years were investigated. Students were observed while writing from their textbooks and skilled workers were observed writing from any available news paper. Photograph of the writing hand was captured with the digital canon camera. The data was analysed using the Statistical Package for Social Sciences (SPSS) 20. Kruska wallis test was used to establish relationship between pencil grip patterns and sociodemographic factors. Handwriting speed was determined by a speed score (letters per minute) and timed for 60 secounds for each participant. A self administered questionnaire was used to obtain data on sociodemographic factors. Results: This investigation demonstrates that gender had a significant effect on pencil grip patterns among secondary students $(\mathrm{p}<0.05)(\mathrm{K} . \mathrm{W}=7.54 . \mathrm{df}=1 . \mathrm{p}=0.01)$. Further observation showed that age and profession had a significant effect on pencil grip patterns among skilled workers at $\mathrm{p}<0.05$ (K.W= $43.09,134.69, \mathrm{df}=3,3, \mathrm{p}=0.00,0.00)$. Conclusion: Findings from this investigation present the dynamic tripod grip as the most predominant grip pattern in the studied population.
\end{abstract}

Keywords: dynamic tripod, pencil grip, delta state, students, skilled workers .

\section{INTRODUCTION}

Operational definitions of numerous pencil grips have been presented in previous research. ${ }^{1,2}$ Pencil grip has been defined via detailed descriptions of the variables constituting the grip ${ }^{3}$ and it commences in the preschool years with pencils, crayons and other writing instruments. Multiple studies had classified pencil grip patterns. ${ }^{4,5}$ Tseng invented a comprehensive pencil grip classification system following her study on pencil grip development on Tawainese preschoolers. ${ }^{5}$ Her study classified pencil grip patterns into primitive, transitional and matured patterns. ${ }^{5}$ Primitive grip patterns observed from previous studies were the radial cross palmer grip, palmer supinate grip, digital pronate grip, brush grip and the grip with extended fingers. ${ }^{4,5}$ The brush grip was named the top tongue grip by Bloote. ${ }^{6}$ It was observed in the brush grip, all fingers gathered along the shaft of the pencil with the eraser end against the palm of the hand ${ }^{5,7}$ The grip with extended fingers, was the first tripod like grip described by Schneck and Henderson. ${ }^{4}$ However from observations by Schneck and Henderson, ${ }^{4}$ it lacked the stability and refinement of the matured grip. Transitional grip patterns noticed were the cross thumb grip, static tripod grip and the four finger grip. ${ }^{4,5}$ The static tripod grip looked bewilderingly similar to the dynamic tripod grip (matured grip pattern). ${ }^{4}$ The stability offered by the fourth and fifth finger, and the intrinsic movement of the hand in the dynamic tripod grip differentiated it from the static tripod grip. ${ }^{4}$ Several authors described the pencil been held with the thumb in opposition to the three fingers as the four finger grip. ${ }^{4,5}$ The lateral and dynamic tripod grips were reported as matured grip patterns by Schneck and Henderson. ${ }^{4}$ In the lateral tripod grip as perceived by Schneck and Henderson, the shaft of the pencil was stabilized along the third finger, steered by the index finger and held by the thumb. ${ }^{4}$ The dynamic tripod grip referred to the use of the thumb, index and middle finger functioning together and performing well coordinated movements ${ }^{9,10,11}$ Dennis and Swinth reported the lateral quadrupod grip as a matured grip and discovered it was functional as the dynamic tripod grip. ${ }^{2}$ Tseng supported studies that found the dynamic quadrupod grip as a matured grip pattern. ${ }^{5}$

The biomechanics of the lateral grips is similar to that of the dynamic grips, movement of the pencil in

Correspondence: Jaiyeoba-Ojigho Jennifer Efe,Delta State University Abraka, Delta State, Nigeria. Email: efemenaojigho@gmail.com. Phone: +234-07017073851. DOI:10.3126/jcmsn.v15i1.1928. Article received: 2018-0222. Article accepted: 2019-02-05. 
both grips originated from the interphalangeal joints of the hand. ${ }^{12}$ The thumb position differentiated the lateral grips from the dynamic grips. ${ }^{9,11}$ Findings from Heidi showed that in the dynamic tripod grips, the thumb opposed as against the lateral grips where the thumb adducted, ${ }^{12}$ the index, middle and ring finger (if a quadrupod grip). There are extensive information on pencil grip patterns amongst several races, and countries, ${ }^{3,4,5,9,11}$ but this is not the case in the Sub-Sahara region of Africa, hence this study to my best of knowledge, will for the first time demonstrate pencil grip patterns among students and skilled workers in Nigeria with special consideration for Delta State and perhaps for the first time in SubSaharan Africa. The investigation also aimed at determining the effect of socio-demographic factors, handedness and handwriting speed on pencil grip patterns. Findings will be relevant to occupational therapist, anthropology and forensic medicine.

\section{METHODS}

This investigation was an empirical cross sectional study which described the diversity of pencil grip patterns among students and skilled workers in Delta State, Nigeria. Population was targeted at Warri, Sapele and Asaba towns which are the largest towns within the three senatorial districts in Delta State . Stratified random sampling was used for this research. Participants were randomly selected within Warri, Asaba and Sapele towns .

A total of five hundred and fourty three volunteers, between the ages of 11-77years were observed for pencil grip patterns. Factors that were considered were age, gender, occupation, ethnicity. preference for handedness, handwriting speed, Schneck and Henderson classification scale on pencil grip patterns and schools registered with the Delta State government . Materials used were A4 sized papers, sharpened HB pencils, erasers, rulers, digital camera and laptop computer. Self administered questionnaire was used to collect information on socio-demographic factors. Ethical approval was obtained from the Research and Ethics Committee of the Faculty of Basic Medical Sciences, Delta State University, Abraka, Delta State, Nigeria. Consent forms were carefully designed to seek the opinion of individuals from eighteen years and above. Students and skilled workers were informed of the aim of the observation, procedure and benefit of the study.

Students were observed for pattern of pencil grip while writing from their textbooks and skilled workers were observed writing from any available
Newspaper. Photograph of the writing hand was captured with the digital canon camera, "CANON 700D/60D,18 MEGA PIXEL". For speedwriting, students and skilled workers were asked to write a 16-letter five word sentence. ${ }^{3}$ The sentence "I want a good friend" was easy to memorize, and after learning the sentence by heart and repeating it they were instructed to keep writing until told to stop. Handwriting speed was timed for 60 seconds for all participants .Data was presented in frequencies and tables to show distribution of pencil grip patterns. Kruska wallis test was used to report relationship between sociodemographic factors and pencil grip patterns. Statistical evaluation was done using SPSS 20 version. Significance was accepted at $\mathrm{P}<0.05$. Handwriting speed was determined by a speed score (letters per minute) for each participant. ${ }^{13}$

\section{RESULTS}

Fig 1,2,3 showed the grip patterns seen among secondary students, tertiary students and skilled workers. Table 1 present grip patterns observed among participants in Warri, Sapele and Asaba towns. Table 1 reports that primitive grip

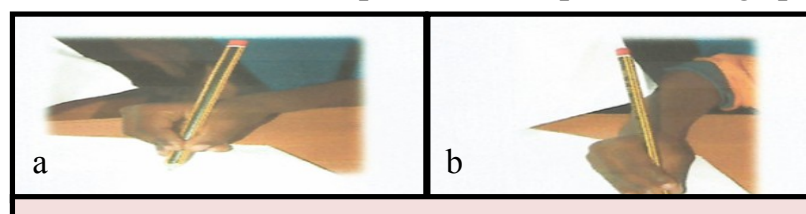

Figure 1. Primitive grip patterns observed among secondary school students (a) grip with extended fingers (b) brush grip.

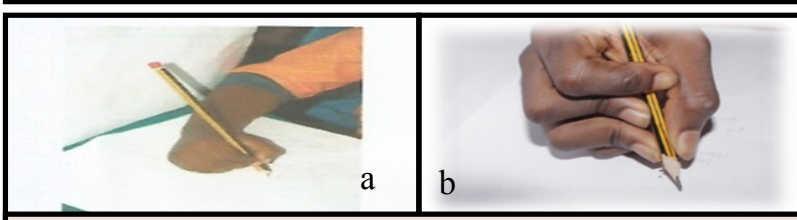

Figure 2. Transitional grip patterns seen among secondary and tertiary school students. (a) static tripod rip (b) four finger grip pattern.

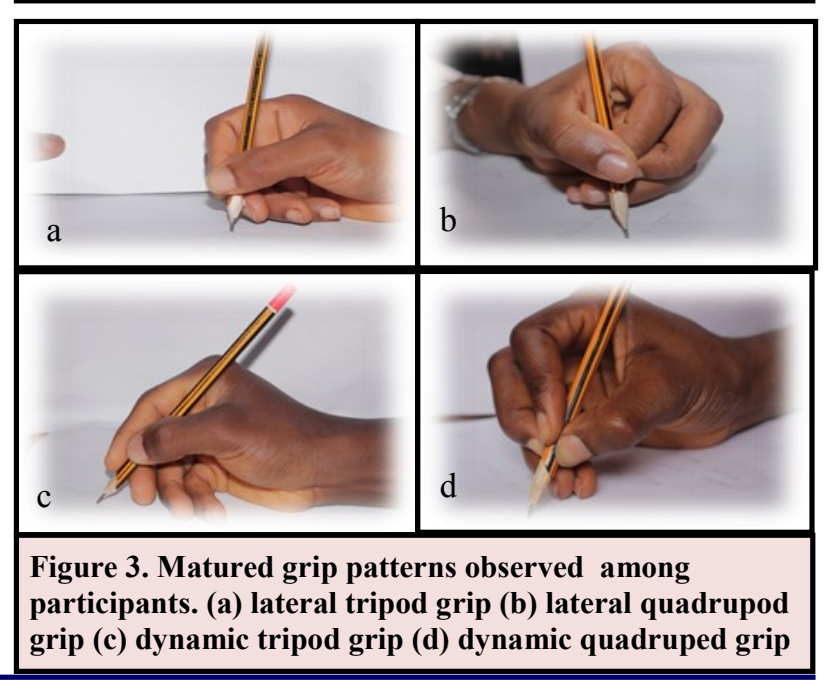


Efe et al. Pencil Grip Patterns of Students and Skilled Workers

\begin{tabular}{|c|c|c|}
\hline PENCILGRIP PATTERNS & SECONDARY STUDENTS & SKILLED WORKERS \\
\hline PRIMITIVE & BG,GEF & \\
\hline TRANSITIONAL & ST,FFG & \\
\hline MATURED & DT,DQ,LT,LQ & DT,DQ,LT,LQ \\
\hline \multicolumn{3}{|c|}{$\begin{array}{l}\text { Key : BG-BRUSH GRIP, GEF- GRIP WITH EXTENDED FINGERS, ST-STATIC TRIPOD GRIP,FFG-FOUR FINGER } \\
\text { GRIP,DT-DYNAMIC TRIPOD GRIP,DQ-DYNAMIC QUADRUPOD GRIP, LT-LATERAL TRIPOD ,LQ-LATERAL } \\
\text { QUADRUPOD }\end{array}$} \\
\hline
\end{tabular}

patterns were seen only in secondary students, transitional grip patterns were observed in secondary and tertiary students while matured grip patterns were noticed in secoundary students, tertiary students and skilled workers.

Table 2 highlighted that a total of 107 males and 106 females aged 11-20 years were investigated while table iii present a total of 68 males and 71 females aged 16-40 years. Primitive grip patterns were observed in a total of 9 secondary students (Table 2). Transitional grips were discovered in a skilled workers (6 males, 7 females) from the Edo tribe adopted the dynamic tripod grip. The tables also showed that secondary students (5 males, 3 females), tertiary students ( 3 males, 1 females) and skilled workers (5 males, 2 females) who adopted the dynamic quadrupod grip were from the Ijaw/ Itsekiri tribes .

The lateral tripod grip was seen in a total of 14 secondary school students, 2 tertiary students and 24 skilled workers from the Urhobo / Isoko tribes while the lateral quadrupod grip was noticed in a

\begin{tabular}{|c|c|c|c|c|c|c|c|c|c|c|c|c|c|c|c|c|c|c|}
\hline \multirow[b]{2}{*}{$\begin{array}{l}\text { AGE } \\
\text { (YRS) }\end{array}$} & \multicolumn{9}{|c|}{ MALE PENCIL GRIP PATTERNS } & \multicolumn{9}{|c|}{ FEMALE PENCIL GRIP PATTERNS } \\
\hline & BG & $\begin{array}{l}\text { D } \\
\text { Q }\end{array}$ & DT & $\begin{array}{l}\text { GE } \\
\text { F }\end{array}$ & LT & ST & LQ & $\begin{array}{l}\text { FF } \\
\text { G }\end{array}$ & $\begin{array}{l}\text { TO- } \\
\text { TAL }\end{array}$ & BG & $\begin{array}{l}\text { D } \\
\text { Q }\end{array}$ & DT & $\begin{array}{l}\text { GE } \\
\text { F }\end{array}$ & LT & ST & LQ & $\begin{array}{l}\text { FF } \\
\text { G }\end{array}$ & $\begin{array}{l}\text { TO- } \\
\text { TAL }\end{array}$ \\
\hline $11-15$ & 1 & 18 & 38 & 3 & 7 & 3 & 3 & 1 & 74 & 3 & 9 & 28 & 2 & 16 & 5 & 9 & 2 & 84 \\
\hline $16-20$ & $\mathbf{0}$ & 8 & 21 & $\mathbf{0}$ & 3 & $\mathbf{0}$ & $\mathbf{0}$ & $\mathbf{0}$ & 33 & $\mathbf{0}$ & 6 & 20 & $\mathbf{0}$ & 6 & $\mathbf{0}$ & $\mathbf{0}$ & 0 & 32 \\
\hline $\begin{array}{l}\text { TO- } \\
\text { TAL }\end{array}$ & 1 & 26 & 59 & 3 & 10 & 3 & 3 & 1 & 107 & 3 & 15 & 48 & 2 & 22 & 5 & 9 & 2 & 106 \\
\hline
\end{tabular}

total of 10 tertiary students from Table 3 . Table 4 displayed that males who used the lateral tripod grip had a mean age of 41.81 while the females had a mean age of 39.73 . total of 4 secondary students and 4 skilled workers from the Igbo/Ika/Ukwani tribes. The dynamic tripod grip was seen among secondary students (3 males, 2 females), tertiary students (3 males, 2

\begin{tabular}{|c|c|c|c|c|c|c|c|c|c|c|c|c|}
\hline \multirow[b]{2}{*}{ AGE } & \multicolumn{6}{|c|}{ MALE PENCIL GRIP PATTERNS } & \multicolumn{6}{|c|}{ FEMALE PENCIL GRIP PATTERNS } \\
\hline & DT & FFG & DQ & $\mathbf{L T}$ & LQ & $\begin{array}{l}\text { TO- } \\
\text { TAL }\end{array}$ & DT & FFG & DQ & $\mathbf{L T}$ & LQ & $\begin{array}{l}\text { TO- } \\
\text { TAL }\end{array}$ \\
\hline $16-20$ & 15 & 3 & 3 & 1 & 0 & 22 & 16 & 2 & 1 & 1 & 1 & 21 \\
\hline $21-25$ & 13 & 0 & 3 & 1 & 1 & 18 & 13 & 2 & 4 & 1 & 2 & 22 \\
\hline 26-30 & 9 & 0 & 3 & 1 & $\mathbf{0}$ & 13 & 10 & 1 & 2 & 2 & 1 & 16 \\
\hline 31-35 & 4 & 1 & 3 & 0 & 0 & 8 & 5 & 0 & O & 0 & 0 & 5 \\
\hline $36-40$ & 5 & 1 & 0 & 0 & 1 & 7 & 5 & 0 & 2 & 0 & 0 & 7 \\
\hline $\begin{array}{l}\text { TO- } \\
\text { TAL }\end{array}$ & 46 & 5 & 12 & 3 & 2 & 68 & 49 & 5 & 9 & 4 & 4 & 71 \\
\hline
\end{tabular}

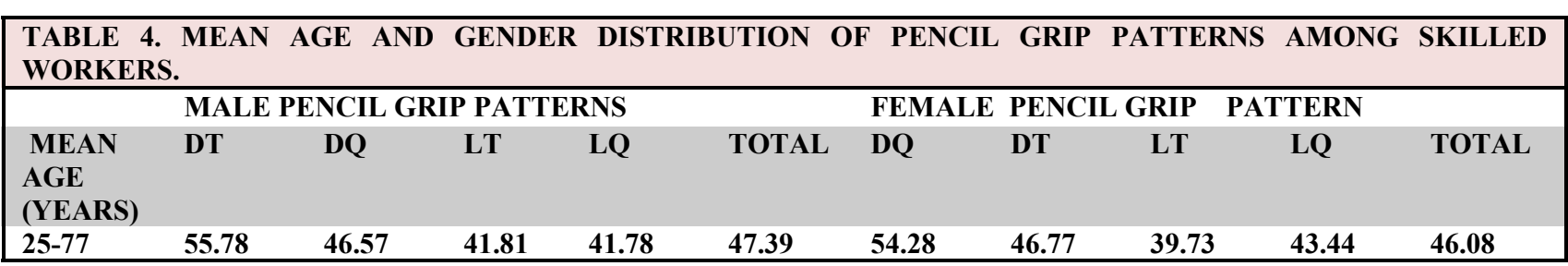

Table 5, 6 and 7 present tribes and gender distribution among participants. This work demonstrates that secondary students ( 2 males, 6 females), tertiary students ( 7 males, 8 females), females) and skilled workers (4 males) from the Yoruba tribe. Among the Hausa participants, findings showed that secondary students (3 males, 3 females) adopted one form of matured grip 
Efe et al. Pencil Grip Patterns of Students and Skilled Workers

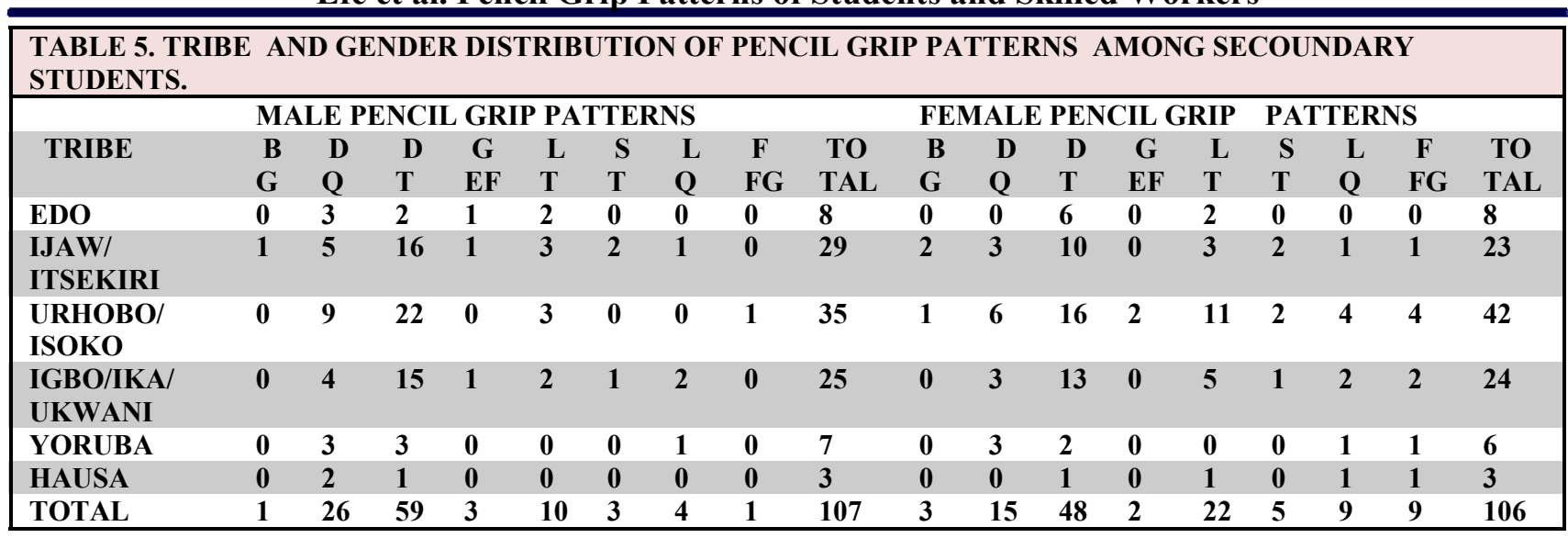

\begin{tabular}{|c|c|c|c|c|c|c|c|c|c|c|c|c|}
\hline PATTERNS & МА & PENC & GRI & ATTI & & & FEI & E PEI & IL G & & & \\
\hline TRIBE & DT & FFG & DQ & LT & LQ & $\begin{array}{l}\text { TO- } \\
\text { TAL }\end{array}$ & DT & FFG & DQ & LT & LQ & $\begin{array}{l}\text { TO- } \\
\text { TAL }\end{array}$ \\
\hline EDO & 7 & $\mathbf{0}$ & $\mathbf{0}$ & $\mathbf{0}$ & 1 & 8 & 8 & 1 & 2 & $\mathbf{0}$ & 1 & 12 \\
\hline $\begin{array}{l}\text { IJAW/ } \\
\text { ITSEKIRI }\end{array}$ & 10 & 3 & 3 & 0 & 0 & 16 & 10 & 0 & 1 & 1 & 2 & 14 \\
\hline $\begin{array}{l}\text { URHOBO/ } \\
\text { ISOKO }\end{array}$ & 13 & 2 & 5 & 1 & $\mathbf{0}$ & 21 & 16 & $\mathbf{0}$ & 5 & 1 & 1 & 23 \\
\hline $\begin{array}{l}\text { IGBO/IKA/ } \\
\text { UKWANI }\end{array}$ & 9 & 0 & 2 & 1 & 0 & 12 & 8 & 1 & $\mathbf{0}$ & 2 & $\mathbf{0}$ & 11 \\
\hline YORUBA & 3 & $\mathbf{0}$ & 1 & $\mathbf{0}$ & $\mathbf{0}$ & 4 & 2 & 1 & 1 & $\mathbf{0}$ & $\mathbf{0}$ & 4 \\
\hline HAUSA & 1 & $\mathbf{0}$ & 1 & $\mathbf{0}$ & $\mathbf{0}$ & 2 & 2 & $\mathbf{0}$ & $\mathbf{0}$ & $\mathbf{0}$ & $\mathbf{0}$ & 2 \\
\hline OTHERS & 3 & $\mathbf{0}$ & $\mathbf{0}$ & 1 & 1 & 5 & 3 & 2 & $\mathbf{0}$ & $\mathbf{0}$ & $\mathbf{0}$ & 5 \\
\hline TOTAL & 46 & 5 & 12 & 3 & 2 & 68 & 49 & 5 & 9 & 4 & 4 & 71 \\
\hline
\end{tabular}

\begin{tabular}{|c|c|c|c|c|c|c|c|c|c|c|}
\hline \multirow[b]{2}{*}{ TRIBE } & \multicolumn{5}{|c|}{ MALE PENCIL GRIP PATTERNS } & \multicolumn{5}{|c|}{ FEMALE PENCIL GRIP PATTERNS } \\
\hline & DT & DQ & LT & LQ & TOTAL & DT & DQ & LT & LQ & $\begin{array}{l}\text { TO- } \\
\text { TAL }\end{array}$ \\
\hline EDO & 6 & 2 & 8 & 1 & 17 & 7 & 3 & 7 & 2 & 19 \\
\hline $\begin{array}{l}\text { IJAW/ } \\
\text { ITSEKIRI }\end{array}$ & 7 & 5 & 5 & 1 & 18 & 5 & 2 & 7 & 1 & 15 \\
\hline $\begin{array}{l}\text { URHOBO/ } \\
\text { ISOKO }\end{array}$ & 5 & 4 & 14 & 3 & 26 & 5 & 5 & 10 & 2 & 22 \\
\hline $\begin{array}{l}\text { IGBO/IKA/ } \\
\text { UKWANI }\end{array}$ & 5 & 3 & 3 & 2 & 13 & 5 & 2 & 2 & 2 & 11 \\
\hline YORUBA & 4 & $\mathbf{0}$ & 3 & 2 & 9 & $\mathbf{0}$ & 1 & 3 & 1 & 5 \\
\hline HAUSA & 3 & 0 & 2 & $\mathbf{0}$ & 5 & 2 & $\mathbf{0}$ & 1 & $\mathbf{0}$ & 3 \\
\hline OTHERS & 2 & $\mathbf{0}$ & 2 & $\mathbf{0}$ & 4 & 1 & $\mathbf{0}$ & $\mathbf{0}$ & 1 & 2 \\
\hline TOTAL & 32 & 14 & 37 & 9 & 92 & 25 & 13 & 30 & 9 & 77 \\
\hline
\end{tabular}

patterns. Skilled workers from the Hausa tribe used only the tripod grips (5 males, 3 females) while tertiary students from the Hausa tribe presented only the dynamic grip patterns ( 2 males, 2 females).

Table 8 reports profession and gender distribution of grip patterns. This research discovered that the dynamic tripod grip was the common pattern seen in 27 male and 20 female Medical Doctors, the dynamic quadrupod was the most frequent pattern among the Teachers ( 12 males, 12 females). Table viii also highlighted the lateral tripod has the most predominant pattern seen among the Lawyers (12 males, 10 females), the Engineers ( 8 males, 7 females) and the Bankers (17 males, 13 females).
Table 9 reveals that the dynamic tripod grip pattern was the most predominant pattern seen in right and left handed secoundary and tertiary students while the lateral tripod grip was common in right and left handed skilled workers. Secondary and tertiary male students who adopted the four finger grip had the fastest handwriting speed from Table 10 . Table 11 showed that gender had a significant effect on pencil grip patterns among secondary school students at $\mathrm{p}<0.05(\mathrm{~K} . \mathrm{W}=7.54 . \quad \mathrm{df}=1$. $\mathrm{p}=0.01$ ). Further observation demonstrates that age and profession had a significant effect on pencil grip pattern among skilled workers at $\mathrm{p}<0.05(\mathrm{~K} . \mathrm{W}=43.09,134.69, \mathrm{df}=3,3, \mathrm{p}=0.00,0.00)$. 
Efe et al. Pencil Grip Patterns of Students and Skilled Workers

\begin{tabular}{|c|c|c|c|c|c|c|c|c|c|c|}
\hline & MA & PENC & GR & PAT & RNS & FEI & E PEI & GRI & TER & \\
\hline PROFESSION & DT & DQ & LT & LQ & TOTAL & DT & DQ & LT & LQ & TOTAL \\
\hline $\begin{array}{l}\text { MEDICAL } \\
\text { DOCTORS }\end{array}$ & 27 & 2 & $\mathbf{0}$ & $\mathbf{0}$ & 29 & 20 & $\mathbf{0}$ & $\mathbf{0}$ & $\mathbf{0}$ & 20 \\
\hline TEACHERS & 3 & 12 & $\mathbf{0}$ & $\mathbf{0}$ & 15 & 5 & 12 & 0 & $\mathbf{0}$ & 17 \\
\hline LAWYERS & 1 & $\mathbf{0}$ & 12 & 6 & 19 & $\mathbf{0}$ & 1 & 10 & 6 & 17 \\
\hline ENGINEERS & $\mathbf{0}$ & $\mathbf{0}$ & 8 & 3 & 11 & $\mathbf{0}$ & $\mathbf{0}$ & 7 & 3 & 10 \\
\hline BANKERS & 1 & $\mathbf{0}$ & 17 & $\mathbf{0}$ & 18 & $\mathbf{0}$ & $\mathbf{0}$ & 13 & $\mathbf{0}$ & 13 \\
\hline TOTAL & 32 & 14 & 37 & 9 & 92 & 25 & 13 & 30 & 9 & 77 \\
\hline
\end{tabular}

\begin{tabular}{|llll|}
\hline \multicolumn{2}{|c|}{ TABLE 9. PENCIL GRIP PATTERNS COMMON AMONG RIGHT AND LEFT HANDED PARTICIPANTS. } \\
\hline HANDEDNESS & SECONDARY STUDENTS & TERTIARY STUDENTS & \multicolumn{1}{l|}{ SKILLED WORKERS } \\
RIGHT & DT(MALES),DT & DT(MALES),DT & LT(MALES),LT \\
& (FEMALES) & (FEMALES) & (FEMALES) \\
LEFT & DT(MALES),DT & DT((MALES),DT & LT(MALES),LT \\
& (FEMALES) & (FEMALES) & (FEMALES) \\
\hline
\end{tabular}

\begin{tabular}{|c|c|c|c|}
\hline HANDWRITING SPEED & SECONDARY STUDENTS & $\begin{array}{l}\text { TERTIARY } \\
\text { DENTS }\end{array}$ & STU- SKILLED WORKERS \\
\hline FASTEST & $\begin{array}{l}\text { FFG-MALES } \\
\text { GEF-FEMALES }\end{array}$ & $\begin{array}{l}\text { FFG-MALES } \\
\text { DT-FEMALES }\end{array}$ & $\begin{array}{l}\text { LT-MALES } \\
\text { LQ-FEMALES }\end{array}$ \\
\hline SLOWEST & $\begin{array}{l}\text { ST-MALES } \\
\text { BG-FEMALES }\end{array}$ & $\begin{array}{l}\text { ST-MALES } \\
\text { BG-FEMALES }\end{array}$ & $\begin{array}{l}\text { DQ-MALES } \\
\text { DT-FEMALES }\end{array}$ \\
\hline
\end{tabular}

\begin{tabular}{|c|c|c|c|}
\hline $\begin{array}{l}\text { SOCIODEMOGRAPHIC FAC- } \\
\text { TORS }\end{array}$ & SECONDARY STUDENTS & TERTIARY STUDENTS & $\begin{array}{l}\text { SKILLED WORK- } \\
\text { ERS }\end{array}$ \\
\hline AGE & 14.09 & 24.77 & 46.79* \\
\hline GENDER & $1.50 *$ & 1.52 & 1.46 \\
\hline ETHNICITY & 3.04 & 3.15 & 2.97 \\
\hline OCCUPATION & & & $2.72 *$ \\
\hline
\end{tabular}

\begin{tabular}{|c|c|c|c|}
\hline VARIABLES & $\begin{array}{l}\text { SECONDARY STU- } \\
\text { DENTS }\end{array}$ & $\begin{array}{l}\text { TERTIARY STU- } \\
\text { DENTS }\end{array}$ & SKILLED WORKERS \\
\hline HANDEDNESS & 1.26 & 1.27 & 1.19 \\
\hline $\begin{array}{l}\text { HANDWRITING } \\
\text { SPEED }\end{array}$ & 2.08 & 58.48 & 52.88 \\
\hline
\end{tabular}

\section{DISCUSSION}

Several authors recommended the dynamic tripod grip as the ideal grip pattern. ${ }^{9,11,12}$ It was described as the pattern in which the shoulder, elbow and wrist stabilization allowed the interphalangeal joints to perform very fine and intricate movements. ${ }^{14}$ Elliot and Connolly, ${ }^{15}$ stipulated that pencil movement in the dynamic tripod grip originated from the interphalangeal joints of the hand and the intrinsic muscles of the hand. It was observed in children between the ages of 4 to 6 years which continued to be refined up to 14 years. ${ }^{4,14,16}$ Findings from this study demonstrates that the dynamic tripod grip was predominant among secondary school students aged 11-20 years. Findings were similar to previous studies carried out in Australia and United Kingdom, among school children. ${ }^{11,16,17}$ From this research, the four finger grip pattern was least observed among secondary students. This study showed that the dynamic tripod grip was predominant among tertiary students aged 16-40 years. Results were in accordance with a study conducted in the USA by Bergmann, (1990). ${ }^{9}$ From Bergmann (1990), ${ }^{9}$ fifty five occupational therapy students and 285 voters were observed signing their names ${ }^{9}$ and 107 medical students were seen taking a written examination. Of the 107 writers, the dynamic tripod grip was noticed in 83 percent while 15 percent adopted the lateral tripod grip. ${ }^{9}$ Of the 340 participants who signed their names, 86 percent used the dynamic tripod and nine percent the lateral tripod grip. ${ }^{9}$ This study also revealed 
that few tertiary students adopted the transitional grip patterns. Findings were similar to Bergmann, (1990). ${ }^{9}$ Tertiary female students from this investigation presented more lateral grip patterns than their male counterparts. Among skilled workers, the lateral tripod grip was predominant in males and females while the lateral quadrupod grip was least observed among the males and females.

The dynamic tripod grip was common among right and left handed secondary students, along with tertiary students. Findings were in concordance to a study carried out on right handed medical and occupational therapist students conducted in the USA. ${ }^{9}$ Result from this study presented the lateral tripod grip has the most predominant grip pattern among right and left handed male and female skilled workers. Result were not in accordance with a previous study carried out among voters in the USA. ${ }^{9}$ This work prooves that gender had a significant effect on secondary students. Findings were not similar to Sasson et al., (1986). ${ }^{17}$ Findings

\section{REFERENCES}

1. Erhardt RP. Developmental Hand dysfunction, Theory, assessment, ant treatment Erhardt Developmental Prehension Assessment. Laurel, Ramsco .1994; Pg 123- 124.

2. Dennis JL \& Swinth Y. Pencil grasp and children's handwriting legibility during legibility during Different-length writing tasks. Amr. J. Occup. Therapy.2001; 55(2): 175-183.

3. Ann-Sofie S. Pencil grip. A descriptive model and four empirical studies. Abo Akademi university press. Abo Finland. Amr. J. Occup. Therapy.1990;90(5):783 $-897$.

4. Schneck CM. \& Henderson A. Descriptive analysis of the developmental progression of grip position for pencil and crayon control in non-dysfunction children. Amr. J. Occup. Theraphy.1990; 44(10):893900.

5. Tseng MH. Handwriting assessment for Chinese elementary school students, World Fed. Occup. Therapist Bulletin.1998; 37: 17-23.

6. Bloote AW. The development of writing behavior. Doctoral dissertation, University of Leiden. 1998.

7. Morrison, A. Occupational therapy for writing difficulties in spina bifida children with myelomeningocele and hydrocephalus. British J. Occup. Therapy.1987; 41:394-397.

8. Bloote AW \& Dijkstra JF .Task effects on young children's performance in manipulating a pencil. Human Mov. Sc. 1989 ; 8:515-528.

9. Bergmann K . Incidence of a typical pencil grasps among no dysfunctional of handwriting adults. Amr. J. Occup. Therapy . $1990 ; 44: 736-740$.

10. Jacobson C \& Sperling L.Classification of hand grip. J.Occup. Med.1976; 395-398,1976.

11.Ziviani J. Children prehension while writing. A pilot also showed that age and occupation had a significant effect on skilled workers. Fluency of handwriting has been defined as writing speed and measured by letters written per minute.13 Findings revealed that variation in pencil grip do not appreciably influence fluency. Findings are in accordance with previous authors on pencil grip and fluency. ${ }^{18-21}$

\section{CONCLUSION}

The dynamic tripod grip was predominant among participants .This showed that matured grip patterns becomes stable and refined with age, However they were also primitive and transitional grip patterns observed in few participants, which could be attributed to the effect of age, gender and ethnicity. Pencil grip pattern will be highly imperative in diagnostic medicine through graphology, forensic medicine.

\section{Conflict of Interest: None}

investigation. Brit. Occup. Therapy J.1982; 45:306-30.

12. Heidi DS. Pencil grip pattern: How critical is it to functional handwriting. Amr. J. Occup. Therapy .2012;13:1-22.

13. Phelps J, Stempel L \& Speck G. The children's handwriting: A new diagnostic scale. J. Edu. Res. 1957 ; 79:46-50.

14. Rosenbloom L \& Horton ME. The maturation of fine prehension young children. Dev. Med. \& child Neuro. 1971;13:3-8.

15. Elliot JM \& Connolly KJ. A classification of manipulative hand movements. Dev. Med. \& Child. Neuro. 1984 ; 26:283-296.

16.Ziviani J. Qualitative changes in dynamic tripod grip between seven and fourteen years of age. Dev. Med. \& Child Neurology.1983 ; 25: 778-782.

17. Sassoon R, Nimmo-Smith I \& Wing AM. An analysis of children's penholds. In H.S R. Kao,G.P. van Galen and R.Hoosain, (Eds.).Graphonomics.NorthHolland:Elsevier.1986;93-106.

18. Tseng MH. \& Cermak SA. The influence of ergonomic factors and perceptual motor abilities on handwriting performance. Amr. J. Occup. Therapy .1993; 47:919-926.

19. Tseng MH \& Murray ES. Differences in perceptual motor measures in children with good and poor handwriting. Occup. Therapy. J. Res. 1994; 14:19-36.

20. Weil MJ \& Cunningham-Amudson SJ. Relationship between visuomotor and handwriting skills of children in kindergarten. Amr. J. Occup. Theraphy1994; 48:982-988.

21. Weintraub N \& Graham S. The contribution of gender, orthographic, finger function and visual motor processes to the prediction of handwriting status. Occup. Theraphy, J.Res.2000; 20:121-140.

Citation: Efe JOJ, Igho OE. Pencil Grip Patterns of Students and Skilled Workers.J CMS Nepal. 2019;15 (1):53-8. 